Western University

Scholarship@Western

FIMS Publications

Information \& Media Studies (FIMS) Faculty

2010

\title{
Inquiring into the Real: A Realist Phenomenological Approach
}

John M. Budd

Heather Hill

Western University, hhill6@uwo.ca

Brooke Shannon

Follow this and additional works at: https://ir.lib.uwo.ca/fimspub

Part of the Library and Information Science Commons

Citation of this paper:

John M. Budd, Heather Hill, and Brooke Shannon, "Inquiring into the Real: A Realist Phenomenological Approach," The Library Quarterly 80, no. 3 (July 2010): 267-284. 


\title{
INQUIRING INTO THE REAL: A REALIST PHENOMENOLOGICAL APPROACH
}

\author{
John M. Budd, ${ }^{1}$ Heather Hill, ${ }^{2}$ and Brooke Shannon ${ }^{3}$
}

\begin{abstract}
The need for postpositivist or antipositivist methods in the social sciences, including library and information science, is well documented. A promising alternative synthesizes critical realism and phenomenology. This method embraces ontological reality in all things, including human and social action. The ontology underlying the realist phenomenological approach recognizes, following Bhaskar, intransitive and transitive objects of knowledge (mind-independent reality and individual and social perceptions of that reality). The synthesis encompasses some particular elements, including perceptions of parts and wholes, the reconciliation of presence and absence, and the essential character of intentionality. Withholding judgment (exercising a particular kind of skepticism) enables inquirers to delve into the historicity and background of action. Potential uses of the method are manifold; some specifics are examined here.
\end{abstract}

The literatures of almost all of the social sciences include authoritative pronouncements that positivism has long since met its demise as a method. Library and information science (LIS), too, includes its share of claims. Even positivism's adherents have admitted to its failures. In spite of the obituaries, there is some reason to believe that a positivistic spirit remains in the social sciences. No one speaks any longer of methodological monism and the reconciliation of synthesis and analysis, but applications betray a false realism in inquiry. In fact, "reification" would be another word for the instances of the positivistic method. In a recent work, Stephen T. Ziliak and Deidre N. McCloskey [1] carefully examine the application of statistical

1. School of Information Science and Learning Technologies, University of Missouri, 303 Townsend, Columbia, MO 65211; Telephone 573-882-3258; Fax 573-884-4944; E-mail buddj@missouri.edu; corresponding author.

2. Assistant professor, Faculty of Information and Media Studies, University of Western Ontario, London, Ontario, Canada N6A 5B7; E-mail hhill6@uwo.ca.

3. School of Information Science and Learning Technologies, University of Missouri, 303 Townsend, Columbia, MO 65211; E-mail bms5yc@mail.mizzou.edu.

[Library Quarterly, vol. 80, no. 3, pp. 267-284]

(C) 2010 by The University of Chicago. All rights reserved. 0024-2519/2010/8003-0005\$10.00 
analyses in studies conducted in the field of economics. Their examination is informed by their entirely correct conjecture that statistical significance has, to a considerable extent, become a surrogate for reasoning. Statistical significance, frequently reported as $t$-, $F$, or $Z$-values, do not signal the substance of relationships between things or the strengths or causal links of these relationships. Ziliak and McCloskey write, "What, a scientist should ask, are the social or personal human purposes activated by [a] belief? What does the belief lead to?” [1, p. 11]. The questions deserve attention in LIS.

An article in the library literature illustrates what Ziliak and McCloskey are speaking of. Frank R. Allen and Mark Dickie employ statistical significance to design a formula for academic library funding. They state, "The purpose of this study is to illustrate a model in which funding of an academic library depends on institutional characteristics" [2, p. 173]. Their intent is to model a funding strategy based on factors external to the library. On the face of it, the notion appears to have potential relevance in higher education fiscal affairs. The variables-number of undergraduate students, number of graduate students, number of PhDs awarded, number of doctoral fields, and number of faculty-should be considered in any general funding model. There are some factors that those variables cannot account for, though, such as the research intensity of the faculty, teaching expectations of faculty (which affect research intensity), research funding attracted, and specifics of the institution's mission (translated into operational imperatives and priorities). In short, the authors do not examine institutional and individual intentionalities that can affect the need for resources. The authors also quantify such variables as governance (private $=1$ and public $=0$ ), which is in no way legitimate. The governance variables are included in the regression analyses. The authors also transform the data to a logarithmic scale, admitting that "the impact on cost of adding the 90th Ph.D. program is probably less than the impact on cost of adding the 20th" [2, p. 173]. The rationale for the presumption is not stated, but cost is not simply a matter of order (which things comes first). It depends on the nature of the program itself. (In other words, it is problematic to assume that all doctoral programs are the same-in objects of study, resources required, potential for the recruitment of students, and other things.) They present actual and model expenditure means graphically, so that little year-to-year difference is apparent. If that is indeed the finding of this study, it seems that the modeling effort yields no benefit. That said, Allen and Dickie also present data for individual members of the Association of Research Libraries. Here the variance is enormous; the University of California, Berkeley, spent about 119 percent more than the model predicted, while Boston University spent 38 percent less than pre- 
dicted. It is not simply that this analysis has no utility; it demonstrates the need for a different way of inquiring into problems in our field.

In another vein, quite a bit of inquiry in LIS does reject the positivistic bent. It tends to rely more on what could be called a hermeneutic construct. Studies in this realm are very difficult to categorize and assess, because uses of hermeneutic or interpretive methods vary greatly in conception and use. On the one hand, Ian Cornelius claims, "Hermeneutics denies the existence of objective facts in the humanities and the social sciences and claims that in gaining understanding of our situation, of one another, and of 'foreign' societies, we are constantly in dialogue and our position becomes transformed by the process of understanding" [3, pp. 18-19]. On the other hand, some hermeneutical studies attempt to identify intersubjective conceptions that can reach some ontological common ground. Cornelius's idea denies ontology and, in so doing, creates serious problems for epistemology. Sometimes explicit, sometimes naive, the antiontology stance is indicative of the neopragmatism articulated by Richard Rorty and others. Not all advocates of a hermeneutic element in LIS inquiry take extreme positions. Joacim Hansson, for one, urges that "the creation of meaning through interpretation of social action and relations can be seen as one of the main prerogatives of contemporary scientific research" [4, p. 111].

Library and information science needs ways to seek and find meaningful and substantive answers to questions that matter. The following is an attempt to forge such a path. As is true of almost all useful methods, there are theoretical and practical sides to method. A different way to inquire is proposed here. It is grounded in realism and in a recognition of ontological necessity. It does not eschew interpretation, though this realist phenomenological approach is amenable to quantitative and qualitative (writ large) analyses, because the method underlying the approach includes a set of conceptual imperatives that guide the inquiry itself. The details of these imperatives, drawn from two foundations, are presented here.

\section{Foundation 1}

The first foundation of the proposed approach is critical realism, as articulated by Roy Bhaskar in a number of works. Bhaskar developed his ideas over many years; this foundation draws from the totality of his work to conceive of the first part of a viable method. One basic tenet of Bhaskar's critical realism is that "the world is constituted by the objects of actual (and, sometimes, possible) experiences" [5, p. 6]. A very attractive part of 
Bhaskar's thought is his understanding of human and social action as "open." He rejects the Humean tradition of asserting laws that operate in closed systems. "This has the consequence that neither the experimental establishment nor the practical application of our knowledge in open systems can be situated. Once we allow for open systems then laws can only be universal if they are interpreted in a non-empirical (trans-factual) way" [5, p. 14]. The rejection of the closed-system requirement necessitates rejection of simplistic empiricism that adheres to narrow definitions of facts. Examination of the ways people ask questions, seek for information, and evaluate what they have found requires the kind of openness Bhaskar advocates.

The openness carries implications for inquiry and method. Human action-people seeking and evaluating information, people seeking knowledge, work within scholarly disciplines, interactions in organizations-cannot be restrictively examined according to superficial characteristics. The action itself has cognitive, intellective, linguistic, communicative, and other elements. The openness, however, does not render human action and the elements that constitute it less real. That is, there is an ontology of cognition, communication, and so forth. The reality of human action cannot be reduced to stimuli and responses, solely physical reactions, or unconscious behavior. Seeking information, for example, is the instantiation of complex self, other (that is, other persons), or externally influenced factors. A teacher's assignment is real and has effects on what students do. What students do, though, is also affected by what they already know, including the difficult to assess "known-unknown." The decisions and choices made by the students are not necessarily subject to a firm set of laws, and there is an explicable reason for resistance to formulation. As Bhaskar writes, "Human action is characterized by the striking phenomenon of intentionality. This seems to depend upon the feature that persons are material things with a degree of neurophysiological complexity which enables them not just, like other higher-order animals, to initiate changes in a purposeful way, to monitor and control their performances, but to monitor the monitoring of these performances and to be capable of a commentary upon them" [6, p. 35].

Intentionality does not signify license. A person acting intentionally has considerable freedom but also acts according to some constraints. The rules of grammar constrain speech, but they by no means determine it. Likewise, rules of logic constrain formal inquiry, but the application of the rules can only occur in certain circumstances. An argument is a formal structure, but that structure does not determine the premise that a particular individual will posit at a given time. One of the forces at work at all times in human and social action is history. History, in this sense, can be big or little (i.e., it can entail events that affect epochs and nations or 
events in the lives of individuals). The influence can result from the collective and shared history of a group (the kind of history that is usually studied) or the history of a person, a family, or an organization.

Not only are ideas in conflict, histories are also at odds with one another. Studies of such things as technical reporting systems will be insufficient; studies of the rhetoric of demand and resistance will be insufficient (although both can contribute to inquiry). Investigations can be conducted in many venues, including actions that take place within institutions and organizations in general (including schools, colleges and universities, government agencies, businesses, and libraries). In short, intentionality is not solipsistic; it exists and operates in contexts that both vary and are constructed (the contexts are almost innumerable, but each has its own structure and form).

Contexts tend to be social (although individualistic context is not impossible). Society, in critical realism, is not an object, separate from people, but neither do people at a particular point in time make society. It both preexists the individuals who live right now (to some extent society is "given" to a person at a point in time) and is shaped by those individuals contemporaneously. Acceptance of this dynamic is important to method; society carries its own ontological meaning-not completely separate from individuals, but with distinctions. For one thing, an individual's intentionality, even if it is as radical as intending transformation of society, may have little impact on social reality. The reason is one of scope and one of kind. Society is composed of the many, each acting intentionally and (although at many times in some substantive purposive agreement) not entirely in concert. Further, society is human and historical; it is a product of what happens now, what has happened, and what future is intended. For these reasons no method that allows, much less embodies, philosophical atomism (the premise that independent entities interact in specified ways, with specified outcomes, as proposed by David Hume) can have efficacy. Bhaskar's criticism of Hume is centered on the reduction to the individual qua individual (that is, the individual as fully representing society and vice versa). The ontological component of this piece of the foundation has apparent applicability to the study and practice of organizing and classifying information.

The critical realist foundation that Bhaskar's thought provides encompasses some essential element of the complete method described here. For one thing, he distinguishes between two distinct objects of knowledge. One he calls "intransitive objects," which are independent of our existence; these are generally material objects or occurrences. For example, a realist believes that the thing we call granite exists whether we have knowledge of it (or even awareness of it) or not. The other object of knowledge is what Bhaskar calls "transitive objects," which "are Aristotelian material 
causes. They are the raw materials of science-the artificial objects fashioned into items of knowledge by the science of the day" [5, p. 21]. Bhaskar says that we cannot imagine a science without transitive objects of knowledge. His claim is based on the historical nature of human knowledge; as he says, it would have been very difficult for William Harvey, working in the seventeenth century, to conceive of the circulation of blood if he had not been aware of the existence of hydraulic pumps [5, pp. 22-23]. From the ontological point of view, the world itself is constituted of transitive and intransitive objects. These two objects of knowledge lead Bhaskar to maintain that his program entails ontological realism and epistemological relativism. His description of epistemological relativism, though, indicates that "epistemological fallibilism" would be a more accurate term.

Method relies on the historical, transitive element. For anyone to be able to ask a new question, one must be cognizant of previous questions and their answers. Method also relies on the ontic (real) structure that defines the world. The structural contribution of Bhaskar is very complex but vital to method. He designs what he calls "four-planar social being" [7, p. 160]. The model represents flow, not static being, so the study of human action, interaction with informing objects, seeking knowledge, communicating informatively, and other acts can be studied as flows. The flows, though, have structure, a structure that accommodates the ontic, the communicative, and the interpretive. The model also serves to illustrate that there are both enabling and constraining forces and that individuals/ society are capable of both the simple reproduction of structures and actions and transforming those structures and actions. The complexity of the social cube holds a great deal of meaning for method. Institutions may be formal entities that, in many cases, preexist the individual, but the involvement of people (praxis) is dynamic. The dynamic participation affects institutions and structures, albeit not always directly or immediately. David Harvey recapitulates the complex interinvolvement of the four planes: "The Community is both the ever-present condition (material cause) and the continually reproduced outcome of self-cultivation (efficient cause), just as self-cultivation is both the conscious production of self and the reproduction of the communal conditions of future self-reproduction" [8, p. 188]. In our field Marianne Wikgren describes the importance of Bhaskar's contribution: "A distinctive feature of a realist philosophy is that ontology (the theory of being, which has strong implications for the conceptions of reality) is seen as distinct from epistemology (the theory of knowledge), which means that scientific theorizing is based on the assumption that there exists a mind-independent reality. In this respect realism differs from empiricism (the view that knowledge derives from experience of the world), and also from idealism (positing thought and language over matter)" [9, p. 12]. 
One particular instance where critical realism can offer analytical assistance is with an element of cognition (mostly transcended in the natural sciences but persistent in the social sciences). There is sufficient evidence that human minds do indeed process information in certain ways. The displaced information-processing model posited simplistic linear routes within the brain that resulted in the aggregation and assimilation of information. The former notion of information processing is evident in a statement by Victor Rosenberg (although he explicitly recognized that there are limitations to the received view): "There is no doubt that a large portion of human behavior associated with information is deterministic, even computer-like" [10, p. 264]. Not all information science thinking and practice has limited itself to the naive cognitive stance. For example, in reviewing work on information processing, Peter Ingwersen suggested that "the shift into a situational context assumes consideration of intentionality and processes of interpretation" [11, p. 13]. While Ingwersen tried to assimilate (among other things) perception and interpretation into information processing and questioned the abilities of computers to capture the unpredictable nature of human cognition and action, he still felt obliged to acknowledge algorithmic processing. At this time the perspective of Ingwersen is the more common, but Rosenberg's determinism has not disappeared.

\section{Foundation 2}

The second foundational anchor of this proposed method is evident from the title of this article. Phenomenology, together with critical realism, provides the basis for rigorous, structured inquiry in LIS and beyond. The most concise definition of phenomenology is offered by Robert Sokolowski: "Phenomenology is the study of human experience and of the way things present themselves to us in and through such experience" [12, p. 2]. That definition requires expansion, though. Experience not only includes, but is necessarily connected to, perception. The experience-perception aspect of being can be examined in two fundamental ways: (1) as an ideal of being, to which human action should be directed so that life can be most fully understood, and (2) as the lived experience of people, examined as people experience and perceive, without a priori imposition or regulation. Method, as discussed here, must adopt the second mode of examination, but it must also adopt the first as a normative and realist direction for experience. The examination, to be complete, has to reconcile parts and wholes-of experience and of reality itself. It must explore presence and absence. It must also apply the lens of intentionality to the study of experience. Such elements can be applied to conceptions of relevance. Even 
here one can discern some common ground between phenomenology and critical realism; the complementarities are what lend credence to this proposed method.

Just as critical realism is more than Bhaskar's idea, so too is phenomenology more than Edmund Husserl's idea. Husserl's program of phenomenology does form the heart of this second foundation, though. Husserl, as does Bhaskar, places ontological reality front and center and, in keeping with Bhaskar, the ontological reality is not bound or constrained by positivistic conceptions: "It is not that that real sensory world is 'recast' or denied, but that an absurd interpretation of the same, which indeed contradicts its own mentally clarified meaning, is set aside. It springs from making the world absolute in a philosophical sense, which is wholly foreign to the way we naturally look upon the world" [13, p. 153]. There is thus a burden on the inquirer to explore reality as it is. The inquirer must reflect on the world as it is plus on our own history in order to reach a complete understanding [13, pp. 198, 200]. The transcendental aspect of Husserl's phenomenology consists of reflecting on both the object perceived and the perceiver's consciousness of the object [13, p. 201]. Phenomenological intentionality is defined, in part, by such reflection: "It is intentionality which characterizes consciousness in the pregnant sense of the term, and justifies us in describing the whole stream of experience as at once a stream of consciousness and unity of one consciousness" [13, p. 222].

Another affinity that phenomenology has with critical realism is negation of the phenomenalist reduction of everything to sense experience. Reality is both more than, and different from, simple sensory experience. Owen Flanagan places the extension of reality within a rejection of imperialistic scientific materialism: "Science has no language to express 'oughts,' unless perhaps they are the 'oughts' of engineering or those of technological practice. . . . Furthermore, if this and many other moral truths are knowable, then there is knowledge that is not scientific" [14, p. 72]. The search for knowledge requires that there be a richer grounding, one that embraces intentionality, perception, and reflection. In phenomenology intentional structure is important; Bhaskar's graphic is illustrative of phenomenology, as well as of critical realism. Situation (including context) contributes to the structure. The structure, for phenomenology, is a vital component of lebenswelt, or lifeworld. In much qualitative research lifeworld is somewhat misconstrued as an individual's lived experience. Lived experience is a component, but lifeworld is the ontological reality in which one experiences life. It is also the complexity of perception and the reflection on experience and perception. Phenomenological analysis is not possible unless the totality of lifeworld is examined. The totality of lifeworld entails implicit skepticism; it is no mere sensation but also the judgment of ex- 
perience. Husserl was clear in later works that this kind of skepticism is necessary-in living and in inquiry into the ways people live lives. Accusations of strong idealism in Husserl's phenomenology are not warranted.

In his last work Husserl [15] elaborated on the concept and practice of epoche, which is vital to this method. Sokolowski offers a useful explanation of epoche: "Reduction, with the Latin root re-ducere, is a leading back, a withholding or a withdrawal. When we enter into this new viewpoint, we suspend the intentionalities we now contemplate" [12, p. 49]. In employing epoche as part of a method, a first step is the recognition and acceptance that epoche does not transform the general actions that are observed (for example, information seeking as a phenomenon). The reason why the epoche $\bar{e}$ as examination does not intrude on general actions is that the reduction is a quest for truth on the subjective terms of the actors. It asks why and seeks to find truth-in-itself. This quest is not often recognized in examination of information seeking or reference transactions, but it could lead to our understanding of the interpretive processes that accompany such actions. Truth-in-itself is in keeping with the epistemological fallibilism of critical realism. The investigation, as a study of subjective consciousness, aims to delve deeper than the superficial evidence of action, to the consciousness itself-insofar as that is possible. Husserl says, "We perform the epoche-we who are philosophizing in a new way-as a transformation of the attitude which precedes it not accidentally but essentially, namely, the attitude of natural human existence which, in its total historicity, in life and science, was never before interrupted" [15, p. 151].

Beyond general actions, epochē is not separate from actors. An understanding of consciousness cannot be accomplished unless consciousness is engaged. Again, this element of phenomenology demonstrates not idealism but realism. Husserl explains the methodological implications of epochē; his words suffice to elucidate its application: "In reciprocal understanding, my experiences and experiential acquisitions enter into contact with those of others, . . . and here again, for the most part, intersubjective harmony of validity occurs, [establishing what is] 'normal' in respect to particular details, and thus an intersubjective unity also comes about in the multiplicity of validities and of what is valid through them . . . but then, whether it is unspoken and even unnoticed, or is expressed through discussion and criticism, a unification is brought about or at least is certain in advance as possibly attainable by everyone" [15, p. 163].

Both phenomenology and critical realism rely on apprehension of the relationship of parts and wholes. The examination of ontological being depends on the apprehension. In fact, it is through such apprehension that the ontology can be appreciated. Anticipating a whole is actually implicit in much of LIS inquiry-finding information, growth of knowledge, even organizational studies of libraries and other agencies. Action, for 
example, is composed of parts; one who seeks information has in mind elements of a question, facets of a search, components of evaluation, and so forth. Likewise, knowledge has parts. The marrying of phenomenology and critical realism enables an inquirer to examine the elements of experience and action that are constitutive parts of a whole, that is, which parts are not independent of the whole but rather define the whole. In order to achieve the end of epoche, the entirety of action and subjective consciousness should be investigated. Conclusions are withheld until such an analysis can be conducted. The evidence Husserl speaks of is, "in an extremely broad sense, an 'experiencing' of something that is, and is thus; it is precisely a mental seeing of something itself" [16, p. 12]. The evidence that is accepted is that which withstands criticism and questioning.

Further, both phenomenology and critical realism depend on the reconciliation of presence and absence. The reconciliation can be expressed deceptively simply: presence and absence are constitutive parts of a whole. The expression may not be very satisfying, though, so some explication follows. First, let us consider Sokolowski's description of absence: "The absences that surround the human condition are of different kinds. Some things are absent because they are future, others because they are contemporary but far away, others because they are forgotten, others because they are concealed or secret, and still others because they are beyond our comprehension and yet are given to us as such: we can know that this is something we do not understand" [12, p. 37]. If we place this into an information-seeking example, it can be seen clearly that the seeker's question inevitably includes absence; it is intended to, at the very least, fill in gaps in both awareness and knowledge and to give further shape to something that already exists in the mind. In the search for knowledge, one is taking the intentionality further; the searcher is open to being reshaped by what is discovered. The reshaping depends on the presence of something, though. This explication is rather simplistic, but it illustrates the fodder for epoche as a component of this method.

\section{Building upon the Foundations}

There are some general aspects of the method that can have universal application and some specific kinds of questions to which the method can be applied. Let us begin with the general. Both of the foundations insist upon inquiry in an open world; closed systems cannot be representations of human and social action. In particular, humans (as actors) interact with one another and with the world. These interactions imply ontology; there is reality to dealings with other people and with the world. As ontological entities, the interactions are thus analyzable, as the thinking, cognizing, 
and affect that are parts of the reality are also open to examination; no mere behavioristic inquiry is likely to be fruitful. A fundamental human act, becoming informed about something, is most effectively examined according to the phenomenological realist approach. Historicity is a component of being informed in several ways: each of us has a history (shared to varying, possibly widely varying, degrees) that shapes how we initiate and proceed throughout an event that can be informative; informative objects have histories that are quite possibly simultaneously epistemologically, ideologically, traditionally, and organizationally shaped; the locus of informing has its history, be it the collective history of libraries (and the individual history of $a$ library), the history that has contributed to the state of a discipline, and the personal history that can affect acceptance or rejection of such things as testimony. The histories are real and deep, and they can be subjected to the phenomenological attitude.

The phenomenological attitude of an inquirer inheres in the entirety of the phenomenological realist approach, although critical realism does not refer to it explicitly. Its counterpoint is the natural attitude, which characterizes most of human thought and action. The natural attitude also characterizes much philosophy and social science research. It is intentional, so there is no question of dismissing or diminishing it as necessary to a lifeworld. Husserl explains: "within the natural attitude . . . the lifeworld could have become the subject matter of a science of its own, an ontology of the lifeworld purely as experiential world" [15, p. 173]. Within the natural attitude one tends not to reflect upon these intentionalities, though; they are taken as givens. A student assigned to write a paper on a particular topic, for example, may leave much unexamined-the possible reasons (intentionalities) for the teacher making that assignment, the location of the assignment within the rest of the course content, the meaning of the assignment's outcome beyond schooling, and other things. The phenomenological realist approach addresses the ego cogito but with special reference to the transcendental reflection on the objects (including the self and other selves) of thought. The phenomenological attitude is necessary to that reflection. It is within the phenomenological attitude that epoche can take place. Examination of what lies beneath and beyond, including beliefs, requires the reflection that transcends the natural attitude.

Some particular examples of application may help elucidate the importance of this method. If we accept that more and more substantive inquiry is needed into school libraries and librarianship, we can see the efficacy of the phenomenological realist approach. A potential aspect of investigation may entail libraries' impact on the reading abilities of students. Libraries may be presumed to be sites of reading, but we may not fully understand school libraries' contributions to students' reading. An element of the examination-of a specific school library or school libraries in gen- 
eral-is the history of libraries' and librarianship's participation in the enhancement of reading ability. That is, one cannot start from the present time without investigating the activeness or passivity of the library and librarian. That history has helped to shape the present state. Likewise, the inquirer will have to investigate the classroom teachers' inclusion (or exclusion) of the library and librarian in the teaching of reading. The actions of the students will be informed by both of these immanent states; the students' self-reflections can be facilitated or retarded by the nature of the state. To explain students' reflection, we can consider Dan Zahavi's observation: "Whereas the world can only appear for a subject, subjectivity does not need the world in order to be. The world, and more generally, every type of transcendence, is relative insofar as the condition for its appearance lies outside itself, namely, in the subject. In contrast the subject, the immanence, is absolute and autonomous since its manifestation only depends on itself" [17, p. 48]. Students, as subjects, can examine their own subjectivity and the effects of the world (learning to read in the rich sense of finding meaning in what is written).

One application of the approach described here can provide a more concrete explanation of its viability. A study was conducted in the spring 2008 semester. Students in a library science course were asked to search for items of potential relevance (and to identify three such items) to a particular topic-"freedom of speech and the First Amendment." There were thirty student responses to the task. A conclusion that can be drawn from the responses is that it is possible for documents to embody some pragmatic aspect of reality (ten listed some common works in their search results). That is, the documents as intentionally created by their authors have syntactic and semantic characteristics that are sufficiently real that a person can retrieve them by means of a search. Further, the documents can be deemed by the searcher as relevant to the question that contributed to the search. That is, the students could apply epoche and apply it in some consistent ways that lead to some shared conclusions. This finding does not contradict any claim that there is more to any document than the intentional structures; it is simply that the intentional structures are sufficiently real as to be sharable. Intentionality that is manifest through syntactic and semantic systems, while not extramental, is a real part of human action. The finding supports a notion that the immanent experiences that humans have include a commonality that is discernible.

The discernment of meaning is possible, in part, because of an ontological character of intentional human communication. The responses to the task posed to the students demonstrate an additional bit of evidence for the ontology. As might be expected by anyone who has taught a course component on searching for information, students are likely, when the topic is imposed upon them, to use the imposed terms as part of the search. 
The respondents in this project did just that but only to a limited degree. The very nature of immanent and transcendent experiences tends to require taking into account the particular intentional identifications applied by the respondents. The processes of perceiving and reflecting entail applying universal concepts to particular instances of the concepts, especially in order to reflect upon the uniqueness of the instances. Insight into an essence-"eidetic intuition" in Husserlian phenomenology-is not mentioned by Bhaskar, but it is implicit in his criticism of the objectivist strain in the social sciences. Sokolowski explains the stages that lead to eidetic intuition:

1. On the first level, we experience a number of things and find similarities among them.

2. On the second level, . . . a kind of identity synthesis now occurs in which we recognize not just similars, but the very same, a "one in many."

3. In our third and final stage, we strive to reach a feature that it would be inconceivable for things to be without [12, pp. 177-78].

When the respondents reported on the reasons for mentioning the three specific items they did, the reporting demonstrates the two characteristics of a single reality. One student searched, in particular, for something on the controversy surrounding the Danish cartoons that satirized Islam. The reasoning employed by the student is apparent in the brief report:

I chose the Malek article [from the Columbia Journalism Review] because it was interesting to hear from the source (Flemming Rose is the culture editor at JyllandsPosten, who solicited the cartoons about Muhammed) about a notable free speech issue. Obviously, the Danes don't work under our First Amendment, but they do have their own guarantees of free speech, and Rose wanted to make a point about free speech by publishing something he knew would be inflammatory. I think it's worthwhile for librarians to reflect on the fact that free speech issues can sometimes be life or death issues.

This report demonstrates something that Bhaskar emphasizes-the social aspect of individual informing. This aspect, he says, embodies, of necessity, a dialectic. The basics of the dialectic entail recursive interaction between society and the individual. The interaction of society is more complicated than the model, but Bhaskar draws it as a means to illustrate continuous (and ideally reflective) interaction within and across space and time. The traversing of space and time allows for (and may even necessitate) alterations in both society and the individual. The respondent above knew something, from some social source (newspaper, television, radio, the Web) about the Danish controversy but wanted to learn more. The knowledge enabled this person to construct a search in which the likelihood of re- 
trieving something relevant was high. Additionally, the student connects the outcomes of the controversy (threats, demonstrations, accusations) with the nature of the cartoons, thereby acknowledging the reflection that is needed for understanding.

Bhaskar also expresses precisely what he means by dialectic: "In its most general sense, dialectic has come to signify any more or less intricate process of conceptual or social (and sometimes even natural) conflict, interconnection and change, in which the generation, interpenetration and class of oppositions, leading to their transcendence in a fuller or more adequate mode of thought of form of life (or being), plays a key role" [7, p. 3]. The modes of dialectic are related to phenomenology; they include parts and wholes, presence and absence, and what Sokolowski refers to as "identity in manifolds" [12, pp. 27-33]. Identity in manifold is exemplified by the need for perception from multiple standpoints or perspectives in order to apprehend a complete thing (a cube, for example) as it is given. The matter of addressing identity in manifolds is also clear in some of the respondents' reports. One of these reports serves to represent the attempt to come to grips, dialectically, with anything that includes multiple perspectives:

I chose this particular article because it was the only result that appeared under the terms I searched under [in a particular database]. It also happened to address the assigned topic toward the college campus, which reflects my interest in the academic library.

I wanted to find an article that would discuss the first amendment in a more active manner, rather than passively discuss the "theory" of what the first amendment could mean. The article struck me as particularly interesting because it dealt with issues of censorship demanded by librarians, rather than the presupposed stance of opposition of material by the community.

I chose the particular result because it seems to present a good example of an article discussing the ramifications that could occur in the digital age and the problems of overcommercializing of the internet and use in a library setting.

The responses illustrate an intentionality that is present at the point of asking the questions and beginning the search. The student frames the issue in a particular way so as to focus on a reality for herself/himself.

Among other things, this response demonstrates the adoption of what can be called a phenomenological attitude toward retrieved information. The phenomenological attitude is an exercise in dialectics as Bhaskar speaks of it. The respondent refers to oppositions in the way that freedom of information can be thought of and in the ways freedom is applied. This respondent eschews the taken-for-granted and follows Bhaskar's advice to "revise our descriptive, taxonomic and explanatory vocabularies in the light of unexpected, and possibly recursive, epistemic and/or ontic change" [7, 
p. 12]. In dialectical critical realism knowledge is not fixed, cannot be reified. For information seeking the implication is that one's process of knowing is not completed by any instrumental acts (such as searching a database). It was mentioned above that one illustration of critical realism is the act of reassessing a document both in light of changing contexts (over time, for instance) and of becoming aware of other documents. This aspect of critical realism is represented very clearly in the respondent's report; no single document (and, by extension, no single statement, image, or claim) is sufficient, given the dialectical nature of knowledge growth. This finding cannot be overemphasized; it carries import for any future research in information seeking and also education in information studies.

\section{Discussion}

The assignment described here is only one possible application of phenomenological critical realism (PCR). The direct interactions between professionals and information seekers and students could provide many opportunities for inquiry. At the very outset there is the formal/structural element of the library as an institution. Within that institution there is praxis that is carried out in specific ways. One question that arises relates to the extent to which there is an acceptance of the information seeker/ student as "other." The forms, attitudes, and outcomes of interactions can be examined. Further, the structural aspects of the queries that are made could be a component of the inquiry. Those aspects are shaped in large part by the nature of the structure, including, among other things, political, economic, social, and associational natures. The nature of the structure might be taken for granted, but phenomenological critical realism insists that it be explicit, so that the fullest meaning can be found. For example, if the institution examined is the public library, there is a capitalist structure that is grounded in taxation; the structure contributes materially (ontologically) to the Being of the public library. All services, collections, access, and interactions between staff and community will be affected by that structure. The four planes that Bhaskar illustrates are connected to the later ideas of Husserl in that there is necessary intersubjectivity, there is reflection on self and other, and there is ontological being manifest through action.

Other kinds of investigation can delve into the existence of libraries themselves. As institutions they do have particular Being and also particular situatedness. That is, the library exists within a context: (1) an academic library exists because of the college or university; it has no purpose apart from that context; (2) a public library exists for the community; its existence is not as fixed as that of an academic library, but it still is situated within the community. There will be inevitable governance relationships between 
the library and the larger institution in which it is located. The common locution "parent organization" carries import that begs for phenomenological examination. More than the rhetorical, the relationship between library and parent is manifest through action. The action has real components—a budget, personnel, policies, a board, and so on. The totality of the structure constitutes a whole composed of parts. The composition of the whole, however, is not self-evident from some device like an organizational chart; interaction is more fluid, and the dialectic is less evident than a chart can illustrate. As Bhaskar says, "if we leave out social structures, or if we only have social structures and we leave out nature or inter-personal relations, then we are in a situation of absence, dialectically erroneous absence" [18, p. 74].

There may be an urge in LIS to seek predictive means of inquiry [19], but that quest may well be quixotic. The phenomenological realist approach takes its cue from Bhaskar, though: "Criteria for the rational development and replacement of theories in social science must be explanatory and non-predictive" [6, pp. 45-46], because of the open-systems nature of social action. With the emphasis on explanation comes a realization that, while social action is characterized by flows, the flows are as abrupt, diverse, and turbulent as are the open systems themselves. Prediction would have to rely on a very different structure. Archer points out clearly that the idea of "unbroken flows would mean a continuity of social groups, membership in the groups, the influences of structure, and the behavior of people in social structures; all of those assumptions are questionable" [20, pp. 72-74]. When it comes to explanation, however, the phenomenological realist approach presents an opportunity to inquire into ontological reality while parsing epistemological conclusions with a fallibilist orientation. Among the many implications of the emphasis on explanation is the practice and theory of classification. This is an integral element of LIS in at least two ways: it is one aspect of the field to provide categorizations of informative objects so that organizational systems can be created, and it is an area of inquiry inasmuch as researchers examine systems of classification and the ways that people themselves categorize informative objects. Bhaskar offers an important observation on the nature and use of classification: "To classify a thing in a particular way in science is to commit oneself to a certain line of inquiry. Ex ante there will be as many possible lines of inquiry as manifest properties of a thing, but not all will be equally promising" [5, p. 210]. An important-perhaps the most important-aspect of the phenomenological realist approach is that classification is a product of a process that enables the emergence of properties (including the properties of thought and action, as well as of objects). For this, and the reasons described throughout this article, this method holds enormous promise for LIS. 
Perhaps most important for LIS, phenomenological critical realism is a sound and practically applicable means of avoiding the trap of positivist or objectivist inquiry. It intentionally includes intersubjectivity and Being, while insisting that ontology obtains. Alva Noë, while not addressing PCR directly, refutes a reductively materialist conception of Being: "It does not seem to us perceivers as if the brain builds up an internal model of the world; rather, it seems to us as if the world is here and we are here in it. ... What guarantees [the world's] availability is, first of all, its actually being here, and second, my possessing the skills needed to gain access to it" [21, p. 140].

\section{REFERENCES}

1. Ziliak, Stephen T., and McCloskey, Deirdre N. The Cult of Statistical Significance: How the Standard Error Costs Us Jobs, Justice, and Lives. Ann Arbor: University of Michigan Press, 2008.

2. Allen, Frank R., and Dickie, Mark. "Toward a Formula-Cased Model for Academic Library Funding: Statistical Significance and Implications of a Model Based upon Institutional Characteristics." College $\mathcal{E}$ Research Libraries 68 (March 2007): 170-81.

3. Cornelius, Ian. Meaning and Method in Information Studies. Norwood, NJ: Ablex, 1996.

4. Hansson, Joacim. "Hermeneutics as a Bridge between the Modern and the Postmodern in Library and Information Science." Journal of Documentation 61, no. 1 (2005): 102-13.

5. Bhaskar, Roy. A Realist Theory of Science. Rev. ed. London: Verso, 1997.

6. Bhaskar, Roy. The Possibility of Naturalism: A Philosophical Critique of the Contemporary Human Sciences. 3rd ed. London: Routledge, 1998.

7. Bhaskar, Roy. Dialectic: The Pulse of Freedom. London: Verso, 1993.

8. Harvey, David L. "Agency and Community: A Critical Realist Paradigm." Journal for the Theory of Social Behaviour 32 (June 2002): 163-94.

9. Wikgren, Marianne. "Critical Realism as a Philosophy and Social Theory in Information Science?" Journal of Documentation 61, no. 1 (2005): 11-22.

10. Rosenberg, Victor. "The Scientific Premises of Information Science." Journal of the American Society for Information Science 25, no. 4 (July/August 1974): 263-69.

11. Ingwersen, Peter. "Cognitive Information Retrieval." Annual Review of Information Science and Technology 34 (2001): 3-52.

12. Sokolowski, Robert. Introduction to Phenomenology. Cambridge: Cambridge University Press, 2000.

13. Husserl, Edmund. Ideas: General Introduction to Pure Phenomenology. New York: Collier Books, 1962.

14. Flanagan, Owen. The Really Hard Problem: Meaning in a Material World. Cambridge, MA: MIT Press, 2007.

15. Husserl, Edmund. The Crisis of the European Sciences and Transcendental Phenomenology. Trans. by David Carr. Evanston, IL: Northwestern University Press, 1970.

16. Husserl, Edmund. Cartesian Meditations. Trans. by Dorion Cairns. Dordrecht: Kluwer, 1999.

17. Zahavi, Dan. Husserl's Phenomenology. Stanford, CA: Stanford University Press, 2003.

18. Bhaskar, Roy. From Science to Emancipation. New Delhi: Sage, 2002.

19. McGrath, William E. "Explanation and Prediction: Building a Unified Theory of Librarianship, Concept and Review." Library Trends 50 (Winter 2002): 350-69. 
20. Archer, Margaret S. Realist Social Theory: The Morphogenetic Approach. Cambridge: Cambridge University Press, 1995.

21. Noë, Alva. Out of Our Heads: Why You Are Not Your Brain, and Other Lessons from the Biology of Consciousness. New York: Hill \& Wang, 2009. 